\title{
CONSTRUCTIONAL FEATURES OF THE STIFFNESS OF SHEARWALLS IN LIGHTWEIGHT STEEL FRAMED BUILDINGS
}

\author{
Oksana ZINKEVYCH ${ }^{1 *}$, Mykola SAVYTSKYI ${ }^{1}$, Andrii ZINKEVYCH ${ }^{2}$
}

\begin{abstract}
For low-rise buildings frame technologies using lightweight thin-wall steel constructions have become significantly widespread. The main influence on a building's spatial rigidity under lateral forces is taken by shearwalls. The necessary stiffness can be accomplished by setting definite constructional parameters that are selected according to the design approach. The purposes of the work are to receive the dependencies of the influence of the constructional features on the stiffness of the shearwalls (using FEM models) and to set the value of the stiffness of the shearwall of any configuration by linking its parameters with the corresponding parameters of a standard shearwall through the established dependencies.

The received dependencies of the effect of the main constructional factors and design approach for the stiffness of shearwalls can be used to provide spatial rigidity. A simplified design approach for estimating the influence of the main constructional features of shearwalls on their rigidity has been developed.
\end{abstract}

\section{INTRODUCTION}

A peculiarity of thin-wall steel construction frames is that in most cases, all the connections of the constructional elements are pin joints. The determinative influence on spatial rigidity under the impact of horizontal forces is taken by shearwalls (horizontal, i.e., ceilings, coverings, and vertical, i.e., walls). [Wei-Wen Yu (2000), Guide (2018)].

The in-plane shear rigidity of shearwalls is provided in the following ways:

- using the cross bracing of galvanized steel strips in a wall panel;

- using framed walls sheathed with sheets or boards.

According to the results of preliminary calculations, the biggest disadvantage of shearwalls with cross bracing is in the significant amount of force in the connections of the bracing with the frame. As the elements are thin-walled, the force received can cause local deformations of sections [Kováč(2015)] and sheet mutilations. The

\section{Address}

1 Department of Reinforced Concrete and Masonry Structures, State Higher Education Establishment "Prydniprovs'ka State Academy of Civil Engineering and Architecture", Dnipro, Ukraine

2 Department of Buildings and Building Materials, Dnipro National University of Railway Transport named after academician V. Lazaryan, Dnipro, Ukraine

* Corresponding author: oksana.zinkevych.dnipro@gmail.com

\section{Key words}

- Lightweight steel framing,

- Framed walls sheathed with sheets,

- Stiffness of shearwalls,

- Sheathing,

- Steel cold-formed thin gauge members. 
Therefore, the necessary stiffness can be accomplished by setting definite constructional parameters that are selected according to a calculation method.

Рекомендации (1980), (guide: 2000 Edition (2000)) proposed methods for estimating the stiffness of shearwalls through their comparison to a model shearwall that consider a limited number of factors and do not show the peculiarities of shearwalls in the frame of lightweight thin-walled steel constructions.

The purposes of this paper are to investigate the dependencies of the influence of constructional peculiarities on the stiffness of shearwalls on the basis of the calculation results for the model shearwalls by the finite element method (FEM) and to set the value of the stiffness for the shearwall of any configuration by linking its parameters with the correspondent characteristics of a standard shearwall through the established dependencies.

\subsection{Factors influencing the stiffness of shearwalls}

Using FEM, a preliminary analysis of the influence of the constructional peculiarities on the indices of the structural behavior of a shearwall was accomplished. For further modeling significant values were used in the dependencies.

According to the results of the previous analysis of the type of frame section (flexural rigidity), the thickness and stiffness of panel sheets do not significantly influence a shearwall's stiffness (conventionally, their direct impact on the shear rigidity of boarding bracing with frame elements was not considered). Therefore, the type of section, width and stiffness of the sheets cannot be considered as factors influencing a shearwall's stiffness (deviation of 5\%).

For further analysis the following factors were taken:

- rigidity of the sheathing connections with the frame members $v_{c}, \mathrm{kN} / \mathrm{cm}$ (is defined experimentally (Iuorio, 2008, Zinkevych, 2013) and depends on the width, elastic modulus, sheet material and diameter of the joint elements);

- aspect ratio of the shearwall dimensions $h / L$ (height / length);

- framing members (studs) spacing;

- spacing of the sheathing connections with the frame elements;

- presence of openings in the shearwall.

The shearwall stiffness $(v, k N / \mathrm{cm})$ was estimated according to the value of the deflection of the top chord of the shearwall under the horizontal load

$$
v=P / f, k N / \mathrm{cm},
$$

where P - concentrated horizontal load (wind, seismic effects) applied to the top chord of the shearwall, $k N$;

$f$-horizontal deflection of the top chord of the shearwall, $\mathrm{cm}$.

To estimate the stiffness of the shearwalls of any size, the value of an effective stiffness of the shearwall (taken per unit of its length, $1 \mathrm{~m})$ is used:

$$
v_{0}=\frac{v}{L}=\frac{P}{f} \cdot \frac{1}{L}, \mathrm{kN} / \mathrm{cm} \cdot \mathrm{m},
$$

with $L$ - length of shearwall, $\mathrm{m}$.

\subsection{Influence of openings in a shearwall}

As most shearwalls (the inner and outer walls of buildings) are used with openings, the influence of their number and configuration has been estimated.

Models with a total equal length of segments (part of a shearwall a)

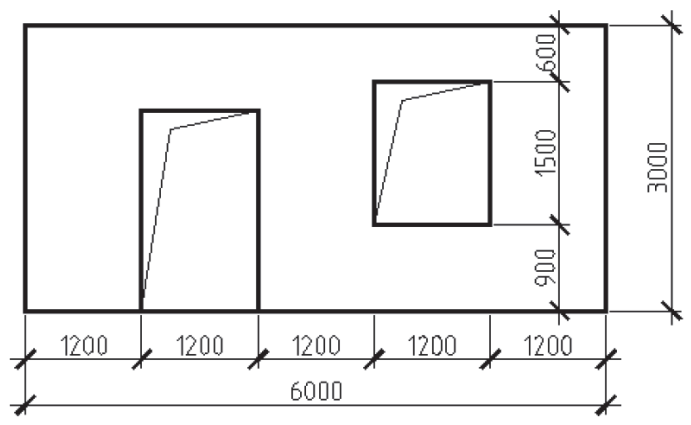

b)

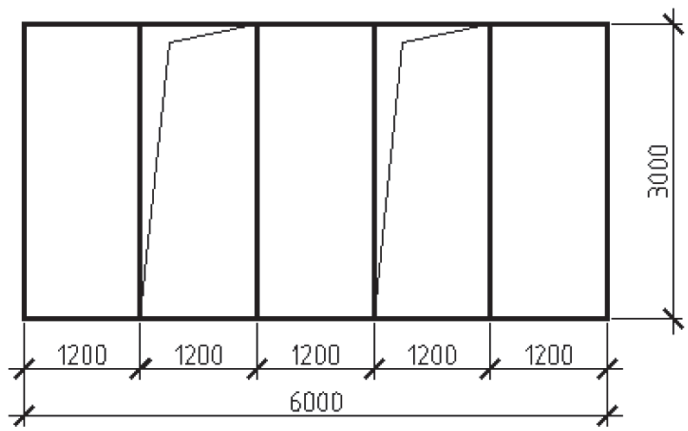

c)

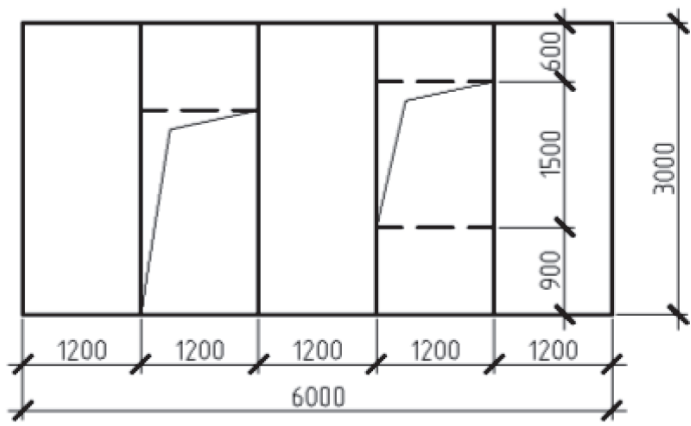

Fig. 1. Types of modeling of the shearwall's sheathing

with the full height of the sheeting) with different lengths of particular segments were considered. Additionally, the influence of ways to model sheathing in a shearwall on the calculation results was estimated for the following:

a) continuous sheeting with cutout openings (Fig. 1a);

b) only segments of a shearwall with sheeting on the entire height were taken into account (Fig. 1b);

c) the sheeting consists of segments of the entire height and parts above and below the openings, that is connected to the frame (Fig. 1c).

A shearwall with continuous sheeting (cutout openings) has the highest degree of stiffness. Such a shearwall is not practical due to the complexity of its fabrication and the limitation of the standard size of the sheets. As a rule, the sheathing of walls above and below openings is made of separate parts that result in seams (Fig. 1c).

According to the results obtained, the stiffness of the shearwalls in cases b and c (Fig. 1) show a slight difference (some decrease for case $b$ ); therefore, to simplify the calculation scheme in general, it is recommended to set the shearwalls by only considering the segments on the entire height (case $b$ ).

Further, a shearwall with openings is considered as a whole set of separate segments with sheathing on the entire height. It is assumed that the stiffness of a certain segment will depend on the aspect ratio 


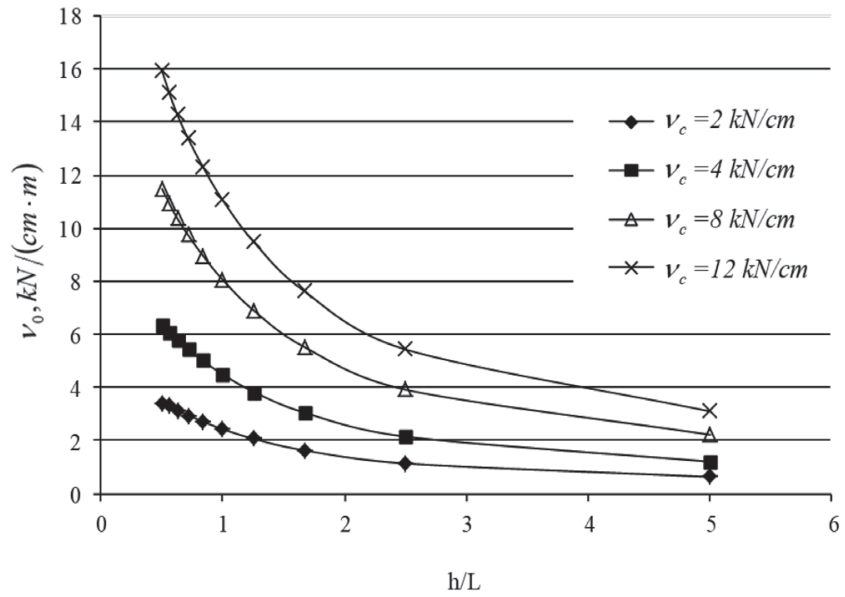

Fig. 2. Dependencies of the effective stiffness of a shearwall related to the aspect ratio and rigidity of the connections

( $h / L$ ) and can be defined by the same dependencies as for shearwalls with the particular $h / L$.

\subsection{Influence of a shearwall's aspect ratio and the rigidity of the connections of the sheathing with the frame members}

The dependencies of an effective stiffness of a shearwall related to the aspect ratio and rigidity of the sheathing connections with the frame members are presented in Figs. 2 and 3.

As the dependencies of the stiffness of a shearwall on the factor analyzed are isoparametric, an approximate equation is given for models with its definite value. The changing value of a factor is considered with the correspondent coefficient.

\subsection{Influence of the stud spacing and the spacing of the connections of the sheathing with the frame members}

There are connections of the sheathing with the frame members around the edge $\left(S_{c e}\right)$ and within the body of the shearwall $\left(S_{c e}\right)$.

An estimation of the influence of stud spacing $\left(S_{S}\right)$ ind the spacing of the connections of the sheathing with the frame members was

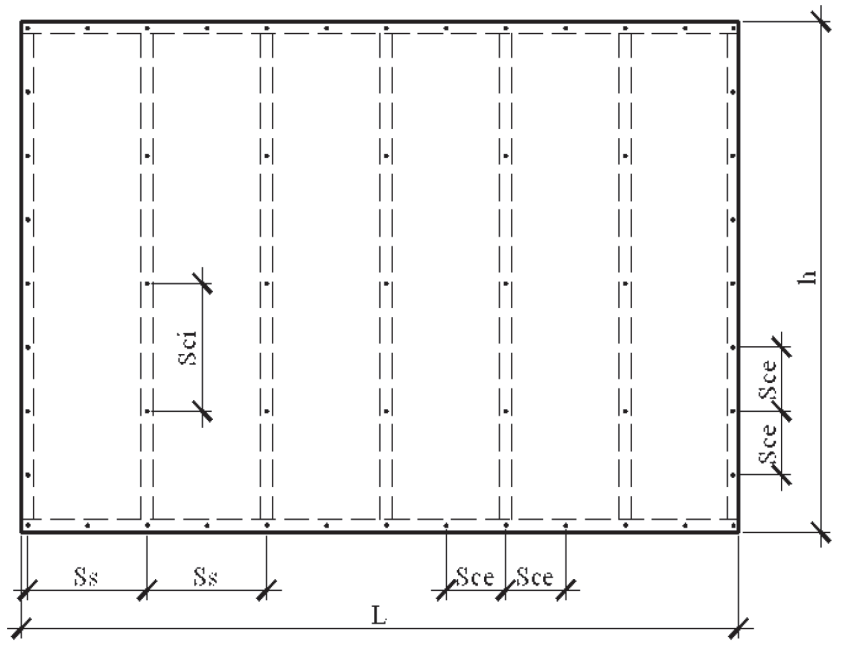

Fig. 4. Scheme of the shearwall model

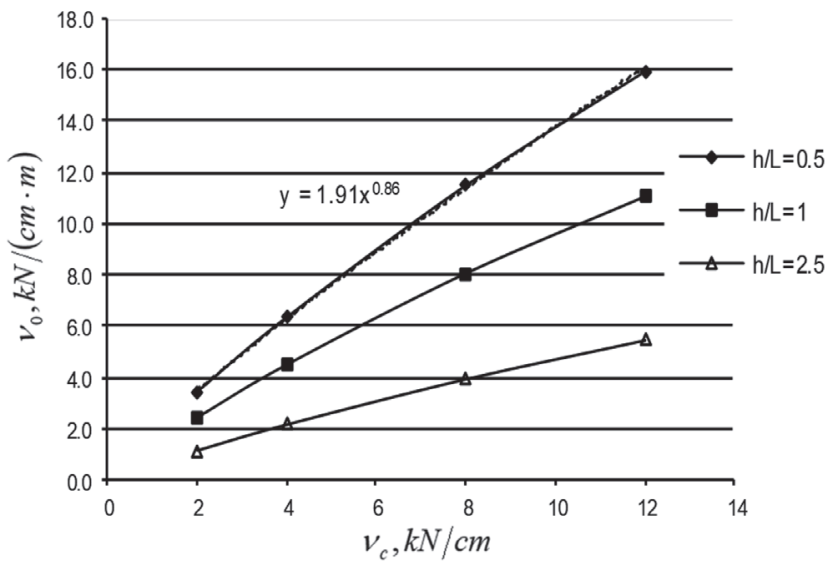

Fig. 3. Dependencies of the effective stiffness of a shearwall related to the rigidity of the sheathing connections with the frame members

accomplished on the shearwall models with the following parameters: length of the shearwall $\mathrm{L}=6000 \mathrm{~mm}$, height $\mathrm{h}=3000 \mathrm{~mm}$, rigidity of the sheathing connections with the frame members $v_{c}=2 \mathrm{kN} / \mathrm{cm}$, the spacing of the sheathing connections with the frame members around the edge of the shearwall $S_{c e}=100 ; 200 ; 300 \mathrm{~mm}$, and the spacing of the connections within the body of the shearwall $S_{c i}=100 ; 200 ; 300$ $\mathrm{mm}$.

The scheme of the shearwall model is presented in Fig. 4.

The dependencies of an effective stiffness of a shearwall related to the stud spacing and connection spacing are presented in Fig. 5 (in the legend: the numerator - the spacing of the connections within the body of the shearwall; the denominator - the spacing of the connections around the edge of the shearwall).

The dependencies of the effective stiffness of the shearwall related to the connection spacing (around the edge and within the body) are given in Fig. 6.

The following conditions were taken into account:

- the dependency of the effective stiffness of the shearwall related to the spacing of the connections within the body of the shearwall was obtained with the spacing of the connections around the edge $S_{c e}=300 \mathrm{~mm}$ (curve for $S_{c i}$ );

- the dependency of the effective stiffness of the shearwall related to the spacing of the connections around the edge of the shearwall was obtained with the spacing of the connections within the body $S_{c i}=300 \mathrm{~mm}$ (curve for $S_{c e}$ ).

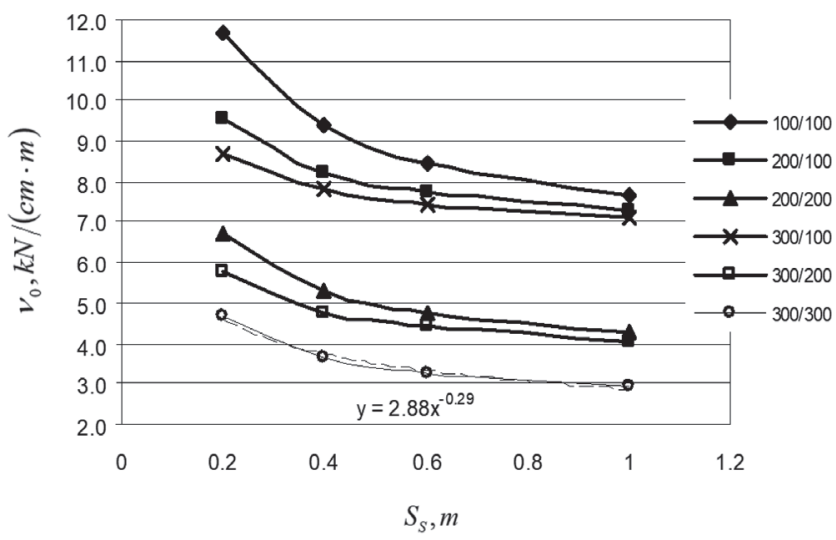

Fig. 5. Dependencies of the effective stiffness of the shearwall related to the stud spacing and connection spacing 


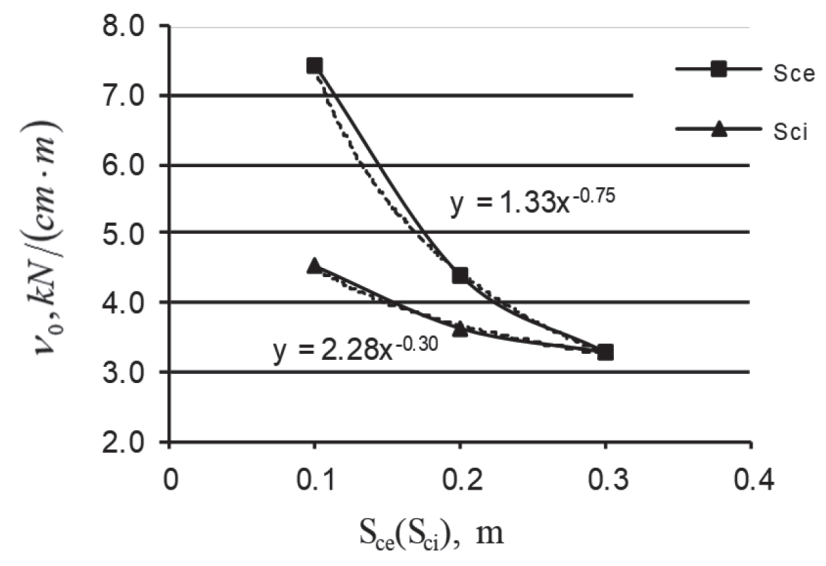

Fig. 6. Dependencies of the effective stiffness of the shearwall related to the connection spacing

All the dependencies (Fig. 6) were obtained for the stud spacing $S_{S}=600 \mathrm{~mm}$.

It was concluded that the effect of the spacing of the connections around the edge on the stiffness of the shearwall is greater then the spacing of the connections within the body of the shearwall.

\section{RESULTS}

On the basis of the correlation dependencies received, a method was developed for the estimation of the shearwalls' stiffness, which permits considering the influence of their constructional peculiarities.

The stiffness per unit of the length of a shearwall $(1 \mathrm{~m})$ by considering its constructional peculiarities is defined as

where

$$
v_{n}=v_{0} \cdot k_{c} \cdot k_{s} \cdot k_{c i} \cdot k_{c e}, \mathrm{kN} / \mathrm{cm} \cdot \mathrm{m},
$$

$v_{0}$ - effective stiffness of a standard shearwall, $\mathrm{kN} /(\mathrm{cm} \cdot \mathrm{m})$;

$k_{c}, k_{s}, k_{c i}, k_{c e}-$ coefficients considering the constructional differences of the shearwall analyzed from a standard shearwall;

$k_{c}$ - coefficient considering the influence of the rigidity of the sheathing connections with the frame members of a shearwall;

$k_{s}$ - coefficients considering the influence of the stud spacing;

$k_{c i}^{s}$ - coefficient considering the influence of the spacing of the sheathing connections with the frame members within the body of the shearwall;

$k_{c e}$ - coefficient considering the influence of the spacing of the sheathing connections with the frame members around the edge of the shearwall;

The rigidity of the shearwall of any configuration is defined as:

$$
v=\sum v_{n i} L_{s i} k_{a r_{i}}, k N / c m
$$

where

$v_{n i}-$ stiffness per unit of the length of the particular segment of a shearwall, $k N /(\mathrm{cm} \cdot \mathrm{m})$;

$L_{s i}$ - length of the shearwall segment (part of the shearwall with sheeting on the entire height), $m$;

$k_{a r_{i}}-$ coefficient considering the aspect ratio of the shearwall segments (height/length).

The values of the coefficients were taken as the relation of the correlation dependencies for the shearwall analyzed and a standard shearwall.

For example, the general definition of the coefficient $k$, which takes into account the influence of the rigidity of the sheathing connections with the frame members of the shearwall is made in the following way (linked to the approximate equation from Fig. 3):

$$
k_{c}=\frac{1.91 \cdot v_{c}^{0.86}}{1.91 \cdot v_{c_{e}}^{0.86}}=\left(\frac{v_{c}}{v_{c_{e}}}\right)^{0.86}
$$

where $v_{c_{e}}$ - rigidity of the sheathing connections with the frame members of the standard shearwall.

The shearwalls of the various configurations (test shearwalls) were tested using the method developed.

The reliability of the method developed was estimated through a comparison of the results received in the calculations of the test shearwalls (design value) with the results of the calculation of the shearwall models with the same configuration by FEM.

The stiffness of the standard shearwall was defined experimentally (in the given paper with a numerical experiment) and used as the basic data for the calculations.

The horizontal deflections of the top chord of the shearwalls under a horizontal load were defined.

The deviations of the results received with the method developed and the FEM calculations of the models do not exceed $15 \%$.

\section{CONCLUSIONS}

A simplified method was developed for estimating the influence of major constructional peculiarities of shearwalls on their stiffness, which permitted the definition of the requirements for the construction at the preliminary stage of devising space-and-planning decisions for a thin-walled steel constructions frame building.

The results received permit to conclude that the calculation method developed is reliable enough for estimating the stiffness of a shearwall and the whole frame.

The dependencies of the influence of the above-mentioned factors and the method of estimating the stiffness of shearwalls can be used for providing spatial rigidity due to:

- setting requirements for the construction of the shearwalls;

- limitating the spacing between shearwalls (decreasing the load space);

- limitating the number of openings in shearwalls. 


\section{REFERENCES}

Wei-Wen Yu (2000) Cold-Formed Steel Design, Wiley, 2000. - 767 p.

IRC Wall Bracing: A Guide (2018) for Builders, Designers and Plan Reviewers. ABTG Research Report No. 1601-01. Available at: https:// www.appliedbuildingtech.com/ system/files/abtgrr_1601-01_irc 2015 wall bracing_guide.pdf.

Kováč, M (2015) Elastic critical axial force for the torsional-flexural buckling of thin-walled metal members: an approximate method. Slovak Journal of Civil Engineering, Vol. 23, No. 1, pp. 23 - 32.

Schafer, B. W.(2013) "Sheathing Braced Design of Wall Studs". AISI-Specifications for the Design of Cold-Formed Steel Structural Members. Available at: https://scholarsmine.mst.edu/cgi/ viewcontent.cgi article $=1114 \&$ context $=$ ccfss-aisi-spec.

Рекомендации (1980) по учету жесткости диафрагм из стального профилированного настила в покрытиях одноэтажных производственных зданий при горизонтальных нагрузках (Recommendations for accounting for the stiffness of diaphragms from steel profiled flooring in the roofs of one-story industrial buildings under the action of a horizontal load). Moscow.
Residential structural design guide: 2000 Edition (2000). Washington, D.C.

Iuorio O. - Schafer B. W. (2008). Compilation of $k$ values, Johns Hopkins University, USA Available at: http:// www.ce.jhu.edu/ bschafer/sheathedwalls.

Zinkevych O. G. (2013). Rational design of low-rise buildings and superstructures' framing from lightweight steel thin-wall constructions, Thesis for the $\mathrm{PhD}$ in technical sciences, specialty 05.23.01 - building structures, buildings and constructions, Prydniprovs'ka State Academy of Civil Engineering and Architecture, Dnipropetrovs'k, Ukraine. 